\title{
线上线下混合的新形态课堂教学研究
}

\section{---以《CAPP 软件应用》课程为例}

祝勇仁

浙江机电职业技术学院

DOI:10.32629/mef.v3i1.524

[摘 要] 在教育信息化时代背景下, 为提高高职学生的职业素养能力, 将线上线下混合的新形态课堂引入教学, 积极探索 将传统、单一的课堂改变为具有多元特征的新形态课堂。本文以CAPP软件应用课程为例，对线上线下的教学现状进行了分 析, 以超星学习通平台为依托进行新形态课堂的教学模式改革研究, 对如何利用学习通平台进行新形态教学做了分析。通过 线下的知识传授与线上的技术技能训练高度融合, 切实提高高职课堂教学质量。

[关键词] 线上线下; 新形态; 超星学习通; 高职

\section{Research on Online and Offline New Classroom Teaching}

\section{--- Take "CAPP Software Application" Course as an Example}

\section{Zhu Yongren}

Zhejiang Institute of Mechanical \& Electrical Engineering

[Abstract] In the context of the educational information age, in order to improve the vocational literacy of higher vocational students, a new form of online and offline classrooms is introduced into teaching, and the traditional and single classrooms are actively explored to be transformed into new form classrooms with multiple characteristics. This article uses the CAPP software application course as an example to analyze the online and offline teaching status. Based on the Superstar Learning platform, it conducts research on the reform of the teaching mode of the new classroom. Through the high-level integration of offline knowledge transfer and online technical skills training, the quality of classroom teaching in vocational colleges is effectively improved. [Keywords] online and offline; new forms; Superstar Learning; higher vocational

混合式教学模式是多种多样方法、形式聚焦一起、融为 一炉，共为之用，它是利用信息技术把传统课堂教学的优势 和网络在线教学的优势结合起来的教学方法。现在主流的定 义是指线上与线下教学模式相结合, 线上指学生利用网络平 台上的教学资源进行自主学习, 线下指教师在课堂上组织并 引导学生学习, 通过线上与线下有机结合完成整个教学过 程。这种线上线下混合的新形态教学模式是贯彻“以生为本、 以用为主” 教育方略, 深入推进高职课堂教学改革, 扭转以 教师为主的传统单一课堂教学特征, 探索与实践具有多元特 征的一种新的教学形态。以 “CAPP软件应用” 课程建设为例, 遵循 “必需、够用” 原则, 打破教材原章节体系, 通过构建 新形态课堂, 将知识传授与技术技能训练高度融合, 探索课 程教学新模式, 切实提高课堂教学质量, 提高学生获得性学 习的能力, 使得高职教育课堂特点得到充分体现。

\section{1 教学现状分析}

在传统教学模式下, 教师讲, 学生听, 学生按时把作业 完成。对于学生是否预习或复习功课, 或是作业的完成情况 无法实时把控, 且学生在遇到问题时无法及时给予解答。由 于完全由教师主宰课堂, 忽视学生的认知主体作用, 不利于
创新思维和创新能力的培养, 更不利于创造型人才的成长。 传统教学方式忽略了学生的主观能动性、创造性, 不能把学 生的主体作用很好地发挥出来, 难以挖掘学习潜力, 使学生 没有独立思考和发挥创造的空间和动力, 全然顾不得自身能 力的培养, 渐渐形成了不爱问、不想问、不会问的习惯, 形成 一种盲目崇拜课本和教师的定式, 使学生的发散性思维和想 象力受到束缚。以 “CAPP软件应用” 课程教学为例, 传统的 授课方式不可能在两节课内按照不同层次的学生取得相同 的学习效果。讲授该课程时需要不同层次的学生按照自身的 学习效果不受时间和空间的限制来进行深度学习。目前的上 课形式以教师讲授软件应用为主, 学生操作为辅的方式, 使 得学生在课堂练习中既得不到有效的指导, 也容易因为困难 而导致不学习的消极心态产生。基于现有教学资源、设备以 及结合信息化建设的手段, 如何实现课堂教学改革, 激发学 生对在学习过程中的兴趣, 提高学习效率, 增强自主学习和 自我学习, 是我们现在所面临解决的重要问题。

\section{2 基于新形态课堂的教学改革}

2. 1 基于信息化平台的教学模式改革

我校积极引入信息化网络教学平台-超星学习通网络平 
台, 推进实施混合式线上线下教学模式改革, 鼓励教师积极 进行混合式课程改革和新形态课堂教学。超星学习通网络平 台主要包含教学管理、课堂活动、课程建设、成绩管理、学 习分析等模块, 教师可以通过该平台对所授课程进行课程内 容管理、学生管理及课程间的共享等。并利用平台对所授课 程进行课程建设, 包含课程学习、学生管理、课程资源建设、 成绩管理、单元学习、课程活动、作业统计、考试统计和课 程积分等。教师可以通过平台发布通知、布置作业、发布线 上学习任务, 在讨论区激发学生积极发帖回帖的积极性, 以 达到学生自主解决问题和分析问题的能力。通过网络教学平 台, 构建学生与教师、学生与学生之间课程内容的沟通, 让 师生之间的沟通不受时间和空间的限制。

线下学习中主要是根据线上的预习、反馈情况, 有目的 进行课堂讲授, 但绝不是对线上内容的重复, 而是结合学生 线上学习的结果对课堂教学内容进行灵活调整。教师通过学 生线上学习过程中遇到的问题和反馈, 有针对性的开展这些 问题进行课堂教学, 培养学生的自主学习能力、分析问题和 解决问题的能力。混合式教学方法充分利用了信息化教学的 先进手段, 把课堂教学延伸到了课外, 能充分调动学生的自 主学习积极性, 结合线上线下测试和练习环节激发学生的学 习兴趣, 达到提高教学效率的作用。

\section{2 新形态教学思路设计}

新形态的教学环境指创设新的教学情景, 模拟用CAPP 软件解决企业的实际工艺设计和工艺信息管理等问题, 创建 学习环境以适应更为主动和逼真的学习环境, 教学项目的设 计力求与真实的工艺设计需求相适应, 以达到学生毕业进入 企业后的零适应过程。教学项目的设计贯穿整个教学内容, 以航空杯注射模的工艺设计为例, 进行工艺的设计、工艺编 辑、工序图的绘制, 以及最后的工艺数据信息汇总, 包括工 时定额、标准件, 外购件明细表的汇总、产品加工路线、设 备加工能力、工序成本信息汇总等, 让学生在真实情景中掌 握应用CAPP软件的能力。必要时, 甚至可以把课堂移到工作 现场, 结合现场实际情况, 锻炼学生应变能力, 促进 “教中 做” “做中学” 和 “学中做” 深度融合, 使得学生在工艺设 计和工艺信息管理方面的专业视野得到开阔的同时, 课堂教 学效率也得到有效提高。

\section{3 新形态教学工具应用}

$\mathrm{CAPP}$ 软件应用线上线下的混合式教学开展基于超星学 习通平台进行开展, 教学过设计主要从以下几个方面进行: 线上线下的预学习和教学活动、课程作业、在线测试、在 线分组练习、答疑讨论, 课程积分、教学预警、课程教学 过程中进行随机抽测、抢答等环节组成。其教学过程图如 下图1所示:

在课前, 教师通过超星学习通App或超星泛雅网络教学 平台发布课前任务, 并设计好一些相关的教学活动。学生 在线自主学习过程中遇到问题可通过App中的群聊和网络 平台中的讨论功能进行在线咨询, 或是把问题记录好带到
线下课堂与教师或同学进行交流。线下上课前, 教师通过 教学平台中的统计功能对学生学习情况进行数据统计分 析, 掌握学习的薄弱环节和大多数人有疑问的地方, 教师 通过数据分析情况, 及时推送相关的学习指导, 让学生做 到充分有效的预习。

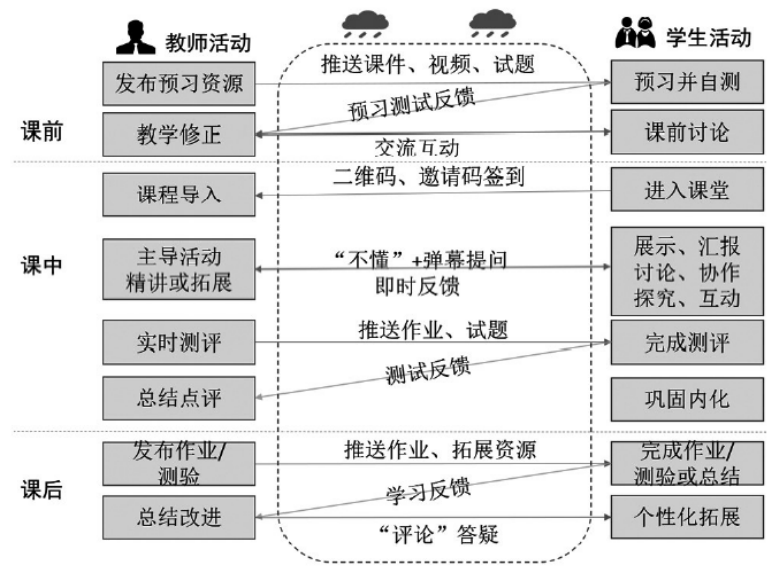

图1 新形态课堂的教学过程

在课堂教学过程中, 教师可以利用课堂活动的签到功能 (拍照签到、位置签到、二维码签到及手势签到) 进行签到, 掌握学生的出勤情况, 并通过软件的成绩管理功能, 根据出 勤学生的出勤率进行积分。教师预先通过平台的添加问卷功 能进行任务分发, 并设置时间, 根据学生的答题情况平台自 动积分, 通过抢答可以让表现突出的同学获得更高的积分, 以区别学生的学习情况。在学习通进行课程音视频的观看、 学习通的访问、参与教师话题讨论、阅读、章节测验以及PBL 项目小组得分等, 这些都可以通过成绩管理模块进行设计, 并区分不同的权重因子, 使得学生的每次活动都可以得到定 量的积分情况加以显示, 这种完善的教学评价体系能对学生 起到正确导向、激励作用，同时通过设置合理的评分权重来 评判学习效果, 让学生对积分给予的学习推动起到了正反馈 的作业, 由于可以设置积分对学生可见, 可以对学生的努力 及时肯定, 使其产生成就感, 更好的激发学生的学习主动性 和积极性。另一方面教师则可以通过对评价结论的分析, 准 确发现教学过程中存在的优势与不足, 对改进课堂教学提供 了推动作用。

\section{3 结语}

在信息化日益发展的今天，构建线上线下的新形态教 学模式, 搭建网络教学平台, 是打破现代职业教育基础模 式的重要思想和技术，更是指引职业教育向未来发展的先 驱者和探路者。不断改革与创新教学模式与方法, 合理利 用信息化技术与工具, 打破传统教学的局限, 让教与学的 积极性和创造性得到充分发挥, 营造高效互动个性化的学 习环境, 充分释放课堂能量, 让课程教学充满活力, 形成 课堂新生态, 全面提升教学质量和教学效果。对于高职教 学的教师应该准确把握线上线下新形态课堂教学模式的核 心, 以实现认知一引导一传授一内化一升华的教学流程, 促 


\section{线上线下混合式教学模式下中职思政课的改革探索}

邹笏

广西交通运输学校

DOI:10.32629/mef.v3i1.528

[摘 要] 教育信息化的实现推进了教学改革的实施, 在中职院校思政课中开始运用线上和线下混合式教学模式。这种教学 模式主要是运用计算机、信息网络、媒体网络，其互动性、开放性、生成性、个性化的特点明显。同时有利于促进资源共享, 使教学质量和效率得到较大幅度的提升。

[关键词] 线上线下; 混合式教学; 思政课

Exploration on the Reform of Ideological and Political Courses in Secondary Vocational Schools under the Online and Offline Mixed Teaching Mode

Zou Yun

Guangxi Transport School

[Abstract] The realization of education informationization has promoted the implementation of teaching reform, and began to use online and offline mixed teaching modes in ideological and political courses in vocational schools. This teaching mode mainly uses computers, information networks, and media networks, its interactive, open, generative, and personalized characteristics are obvious. At the same time, it is conducive to promoting resource sharing and greatly improving the quality and efficiency of teaching.

[Keywords] online and offline; mixed teaching; ideological and political lessons

思政课要想有效开展, 需在实施时遵循学生实际生长 规律, 根据实际情况作出变化, 紧跟时代脚步。在新媒体 和新技术不断发展过程中, 需对思政教育教学方法进行不 断改进, 进而提升思政课在开展时对学生的吸引力。

\section{1 线上线下教学模式的主要内涵与特征}

从内涵来讲, 线上教学是利用互联网和网络空间实施 的教学活动, 这种教学活动主要是对于线上而言, 是将教 学时空延伸到虚拟的空间中, 将互联网中的先进工具和教 学资源之间结合在一起, 进而实现教学育人。这种教学模 式的运用能够使学生积极参与到学习中, 并且实现个性化
学习。从特征来讲, 这种教学模式能够使教材在内容上的 局限性得以打破, 教学内容更加丰富, 教学元素更加多元, 有利于整个教学内容在体系上的重构。其次, 这种教学模 式结合了传统教学和信息技术的优势, 不仅使传统教学模 式中师生之间面对面交流的优点得以发挥, 也使传统教学 模式中的不足得到了补充, 可以运用线上答疑和微视频等 多种形式。最后, 在进行教学评价时教师可以运用线上方 式, 对课程考核结果进行有效记录, 进而将考核过程和考 核结果有效结合在一起, 使考核更加多元化和系统化。

\section{2 当前中职院校思政课教学中存在的主要问题}

进学生的职业能力发展和职业素养的提高, 为职业教育的 改革奉献自己的聪明才智。

[参考文献]

[1]王鹰汉,胡华海.线上线下混合式教学在高职院校教学 中有效性探究[J].湖北开放职业学院学报,2019(261):151-152.

[2]钱炳芸. 基于新形态课堂的城市轨道交通安全管理课 程教学设计与实践 [J].河北职业教育,2019(12):63-66.

[3]李建荣.线上线下混合式教学探索与实践 [J].教育教 学论坛,2019(9):164-165.

[4]尤光辉,蒋立正,王海涛. 基于数字化平台的新形态课 堂教学改革一以《工业机器人操作、应用与维护》课程为 例[J].科技资讯,2019(32):123-124.

[5]杨华.线上线下教学背景下计算机教学的有效开展
[J].科技经济导刊,2019(34):158.

[6]傅丽贤,黄会明.基于雨课堂的高职新形态课堂教学 改革实践一以 “汽车保险与理赔”课程为例 [J]. 金华职业 技术学院学报,2019(11):47-52.

\section{作者简介:}

祝勇仁 (1976--), 男, 汉族, 浙江江山人, 硕士, 副 教授, 研究方向: 机械设计及理论、制造业信息化工程技术、 高职教育等。

基金项目:

浙江机电职业技术学院2019年学院课堂教学改革(新形 态课堂专项)重点培育项目 “CAPP软件应用线上线下混合教 学模式研究” (编号A-0152-19-3117)。 